\title{
Excitation and Inhibition Compete to Control Spiking during Hippocampal Ripples: Intracellular Study in Behaving Mice
}

\author{
DDiel F. English, ${ }^{1}$ Adrien Peyrache, ${ }^{1}$ Eran Stark, ${ }^{1}$ Lisa Roux, ${ }^{1}$ DDaniela Vallentin, ${ }^{1}$ Michael A. Long, ${ }^{1,2}$ \\ and $\oplus^{-G y o ̈ r g y ~ B u z s a ́ k i ~}{ }^{1,2}$ \\ ${ }^{1}$ NYU Neuroscience Institute, School of Medicine, and ${ }^{2}$ Center for Neural Science, New York University, New York, New York 10016
}

\begin{abstract}
High-frequency ripple oscillations, observed most prominently in the hippocampal CA1 pyramidal layer, are associated with memory consolidation. The cellular and network mechanisms underlying the generation of the rhythm and the recruitment of spikes from pyramidal neurons are still poorly understood. Using intracellular, sharp electrode recordings in freely moving, drug-free mice, we observed consistent large depolarizations in CA1 pyramidal cells during sharp wave ripples, which are associated with ripple frequency fluctuation of the membrane potential ("intracellular ripple"). Despite consistent depolarization, often exceeding pre-ripple spike threshold values, current pulse-induced spikes were strongly suppressed, indicating that spiking was under the control of concurrent shunting inhibition. Ripple events were followed by a prominent afterhyperpolarization and spike suppression. Action potentials during and outside ripples were orthodromic, arguing against ectopic spike generation, which has been postulated by computational models of ripple generation. These findings indicate that dendritic excitation of pyramidal neurons during ripples is countered by shunting of the membrane and postripple silence is mediated by hyperpolarizing inhibition.
\end{abstract}

Key words: action potential threshold; hippocampus; inhibition; intracellular in vivo recording; oscillations; sharp wave ripples

\section{Introduction}

A prominent physiological pattern involved in memory consolidation is the sharp wave-ripple complex, which occurs mainly during non-rapid eye movement sleep, immobility, and consummatory behaviors (Buzsàki, 1983; Wilson and McNaughton, 1994; Karlsson and Frank, 2009). During these events, population bursts from multiple locations of the hippocampal CA3 region depolarize dendrites of CA1 neurons. This depolarization is indicated by a negative sharp wave in the dendritic layers (Buzsàki, 1983; Buzsáki, 1986). The excited target CA1 network, in turn, induces a short-lived fast oscillatory event in the pyramidal layer, known as a "ripple" (140-180 Hz; O'Keefe and Nadel, 1978; Buzsáki et al., 1992). Only a small subset of pyramidal neurons participates during ripples (Buzsáki et al., 1992; Csicsvari et al., 1999b; Sullivan et al., 2011) and their sequential activity is often similar to firing sequences of the same neurons during learning and exploration (Wilson and McNaughton, 1994; Kudrimoti et al., 1999; Nádasdy et al., 1999; Lee and Wilson, 2002; Johnson and Redish, 2005; Foster and Wilson, 2006; O’Neill et al.,

Received June 23, 2014; revised Oct. 22, 2014; accepted 0ct. 23, 2014.

Author contributions: D.F.E., A.P., E.S., L.R., and G.B. designed research; D.F.E., E.S., and L.R. performed research; D.V. and M.A.L. contributed unpublished reagents/analytic tools; D.F.E., A.P., E.S., and L.R. analyzed data; D.F.E., A.P., and G.B. wrote the paper.

This work was supported by National Institutes of Health Grants NS034994 (G.B.), MH54671 (G.B.), NS074015 (G.B.), and NS075044 (M.L.); the Mathers Foundation (E.S.); the Rothschild Foundation (E.S.); the Human Frontiers in Science Project LT-000346/2009-L (E.S.); the Machiah Foundation (E.S.); Human Frontier Science Program Fellowship LT000160/2011-L (A.P.); and European Molecular Biology Organization Fellowship ALTF 1345-2010 (A.P.). The authors declare no competing financial interests.

Correspondence should be addressed to György Buzsáki at the above address. E-mail: gyorgy.buzsaki@nyumc.org.

DOI:10.1523/JNEUROSCI.2600-14.2014

Copyright $\odot 2014$ the authors $\quad 0270-6474 / 14 / 3316509-09 \$ 15.00 / 0$
2006; Diba and Buzsáki, 2007; Gupta et al., 2010; Jadhav et al., 2012; Singer et al., 2013; Wikenheiser and Redish, 2013; Mizunuma et al., 2014). Selective elimination of ripples after learning results in impaired memory performance (Girardeau et al., 2009; Ego-Stengel and Wilson, 2010; Jadhav et al., 2012). Intraripple organization of pyramidal neurons is aided by a delicate inhibitory selection process (Klausberger and Somogyi, 2008; Ellender et al., 2010; Papatheodoropoulos and Koniaris, 2011).

According to a prominent computation model, axo-axonal gap junctions connect CAl pyramidal neurons into a sparse electrically coupled network, resulting in spikes from the axonal plexus propagating antidromically to the soma (Traub and Bibbig, 2000; Schmitz et al., 2001; Traub et al., 2012). This model is primarily supported by in vitro slice experiments, including the demonstration of antidromic spikes recorded intracellularly in pyramidal cells during ripples in vitro (Papatheodoropoulos, 2008; Bähner et al., 2011), and the observation that gap junction blockers abolish ripples in vitro (Draguhn et al., 1998; Schmitz et al., 2001; Maier et al., 2003) and in vivo (Ylinen et al., 1995). Competing models require inhibition and interactions between excitation and inhibition (Buzsáki et al., 1992; Whittington et al., 1995; Ylinen et al., 1995; Traub et al., 1996; Brunel and Wang, 2003; Geisler et al., 2005; Rácz et al., 2009; Taxidis et al., 2012; Varga et al., 2012; Hájos et al., 2013; Chiovini et al., 2014; Karlócai et al., 2014). Interpretation of in vitro studies is constrained because the exact activity in vitro may depend on a variety of experimenter-set conditions. Furthermore, many in vitro studies investigated CA3 ripples, which are neither prominent in vivo nor coherent with CA1 ripples (Sullivan et al., 2011). Previous intracellular studies investigating ripples in vivo were performed only under the influence of drugs (Ylinen et al., 1995; Kamondi et al., 
Table 1. Properties of recorded neurons

\begin{tabular}{|c|c|c|c|c|c|c|c|c|c|c|c|c|}
\hline & \multirow{2}{*}{$\begin{array}{l}\text { Time } \\
(\min )\end{array}$} & \multirow{2}{*}{$\begin{array}{l}\text { Resting } \\
\operatorname{Vm}(\mathrm{mV})\end{array}$} & \multirow{2}{*}{$\begin{array}{l}\text { Firing rate } \\
\text { overall }(\mathrm{Hz})\end{array}$} & \multirow{2}{*}{$\begin{array}{l}\text { Outside } \\
\text { ripples }\end{array}$} & \multirow[b]{2}{*}{ In ripples } & \multicolumn{2}{|c|}{ LFP ripples } & \multicolumn{2}{|c|}{ Vm ripples } & \multirow{2}{*}{$\begin{array}{l}\text { Input resistance } \\
(\mathrm{M} \Omega)\end{array}$} & \multirow{2}{*}{$\begin{array}{l}\text { Electrode impedance } \\
(\mathrm{M} \Omega)\end{array}$} & \multirow{2}{*}{$\begin{array}{l}\text { Depth } \\
(\mu \mathrm{m})\end{array}$} \\
\hline & & & & & & Count & Percentage with spikes & Count & Percentage with spikes & & & \\
\hline \multicolumn{13}{|c|}{ Neuron } \\
\hline 3 & 51.00 & -56.97 & 11.10 & 10.91 & 30.59 & 376 & 65 & 50 & 98 & 59.03 & 165 & 1500 \\
\hline 4 & 12.15 & -58.61 & 0.65 & 0.66 & 0.46 & 216 & 1 & 2 & 100 & Not available & 100 & 1800 \\
\hline 5 & 11.37 & -76.13 & 1.05 & 1.00 & 5.40 & 105 & 15 & 10 & 40 & 46.35 & 117 & 1400 \\
\hline 8 & 66.23 & -67.49 & 4.10 & 4.09 & 7.49 & 138 & 20 & 56 & 39 & 42.95 & 200 & 1400 \\
\hline 9 & 161.92 & -55.57 & 0.53 & 0.51 & 3.96 & 952 & 12 & 294 & 33 & 40.58 & 150 & 1500 \\
\hline 10 & 32.58 & -67.45 & 4.70 & 5.12 & 40.31 & 86 & 66 & 9 & 100 & 42.14 & 185 & 1515 \\
\hline 11 & 5.55 & -66.94 & 1.48 & 1.35 & 10.61 & 66 & 29 & 12 & 17 & 35.71 & 90 & 2000 \\
\hline Mean & 37.97 & -65.93 & 2.90 & 2.85 & 12.81 & 228.55 & 28.27 & 47.73 & 48.36 & 44.23 & 134.55 & 1555.91 \\
\hline SD & 46.37 & 8.15 & 3.15 & 3.15 & 13.34 & 256.35 & 24.67 & 83.59 & 34.94 & 6.82 & 35.98 & 189.96 \\
\hline
\end{tabular}

1998). To examine the nature of spike generation and the role of inhibition in controlling spiking during ripples, we recorded the membrane potential of CA1 pyramidal cells during ripples in freely behaving mice. We demonstrate that, in vivo, action potentials in ripples are orthodromic and inhibition produces sparse spiking, despite consistent depolarization.

\section{Materials and Methods}

Sharp electrode microdrive and surgery. Ultralight $(\sim 2 \mathrm{~g})$, head-mounted sharp electrode microdrives, originally developed for recordings from zebra finches (Long et al., 2010), were used in these experiments. Microdrive dimensions were as follows: height, $\sim 20 \mathrm{~mm}$; length, $\sim 10 \mathrm{~mm}$; width, $\sim 6 \mathrm{~mm}$; length of travel, $\sim 6 \mathrm{~mm}$. Ground and interface wires were solid silver (0.008 inch diameter; part \#782000, A-M Systems. Electrode advancement was via a miniature DC linear actuator (brushless DC micromotor with 125:1 planetary gear reduction; part \#0308Y0001, Micromo). Electrode stabilization was provided by sharpened nylon screws mounted in miniature brass hex-nuts (binder head nylon screws, part \#NBB00908; brass hex nuts, part \#HNBS0090, Micro Fasteners). Microdrive implantation was performed under isoflurane anesthesia, $24-72 \mathrm{~h}$ before recording, in 2-6-month-old male C57BL/6J mice (The Jackson Laboratory). The scalp was removed and the bone was treated with 3\% hydrogen peroxide and an etchant/adhesive (OptiBond, Kerr), following which the microdrive, loaded with a dummy electrode, was placed such that the electrode tip was located at -2 to $-2.5 \mathrm{~mm}$ posterior from bregma and $1-2.5 \mathrm{~mm}$ lateral from the midline fissure. The drive was then affixed to the skull using dental cement (Unifast Trad, GC America). A craniotomy was made ipsilateral to the intracellular recording site, -2.5 to $-3 \mathrm{~mm}$ posterior from bregma and -1.5 to $-2.5 \mathrm{~mm}$ lateral from the midline fissure, for implanting extracellular recording electrodes. The footprint of the microdrive limited the minimum distance between the intracellular and extracellular recording sites, which varied from 0.5 to $1 \mathrm{~mm}$ in different experiments. Extracellular electrodes for local field potential (LFP) recording were made from eight $20 \mu \mathrm{m}$ tungsten wires (California Fine Wire), twisted into a single octrode. Two chlorinated silver wires (0.008 inch silver wire, A-M Systems) were placed under the skull above the cerebellum on the side contralateral to recording and served as reference and ground. Extracellular recording wires were connected to an Omnetics (Omnetics Connector) connector affixed to the skull with dental cement as above. Intracellular recording wires and wires for controlling the microdrive were connected to a second Omnetics connector mounted on the microdrive. Animals were allowed to recover for $24-36 \mathrm{~h}$. During the recovery period, the extracellular recording sites were checked for the presence of hippocampal ripples. If no ripples were recorded on any of the wire electrodes (i.e., they missed the target CA1 pyramidal layer), the mouse was not included in the present experiments.

To mount the intracellular recording electrode in the microdrive and to make the craniotomy through which to place the electrode, another brief surgery (5-20 min) was performed under isoflurane anesthesia on the day of recording. During this surgery a $0.1-0.2 \mathrm{~mm}$ craniotomy was made and the dura mater was removed. A well was created around the craniotomy using a biocompatible two-part silicone elastomer (KwikCast, World Precision Instruments), which was then filled with 10,000 cs silicone fluid (E200, Dow Corning) to protect the brain and stabilize the recording pipette. Pipettes for intracellular recording (90-200 M 2 ; Table 1) were pulled from borosilicate glass (part \#BF100-50-100; outer diameter, $1 \mathrm{~mm}$; inner diameter, $0.5 \mathrm{~mm}$; Friedrich \& Dimmock), using a P-97 Flaming/Brown micropipette puller (Sutter Instrument), and filled with 1 or $3 \mathrm{~m}$ potassium acetate (P1190, Sigma-Aldrich), and in some cases $2 \%$ biocytin (B4261, Sigma-Aldrich), as described previously (Ylinen et al., 1995; Quilichini et al., 2010). After placement of the electrode in the microdrive, the animal was removed from anesthesia and placed in a Plexiglas recording chamber (footprint, $30 \times 30 \mathrm{~cm}$; walls, 25 $\mathrm{cm}$ ) with a $20-\mathrm{cm}$-diameter running wheel built into one wall. Animals awakened in 1-5 min. The intracellular electrode was lowered manually by the motorized microdrive through the cortex in 10-20 $\mu \mathrm{m}$ steps over the following 10-45 min. Impalement of hippocampal neurons was attempted after the animal had been awake for $\geq 30 \mathrm{~min}$, using electromechanical "buzzing" (ringing the capacitance compensation circuit) as described previously in anesthetized animals (Ylinen et al., 1995). No effort was made to restrict the movement of the animal during neuron impalement or at any other time, and animals were observed to perform normal behaviors, including grooming, wheel running, and sleep. For tracking the position of the animals, two small light-emitting diodes (1.5 $\mathrm{cm}$ separation), mounted above the headstage, were recorded by a digital video camera and sampled at $30 \mathrm{~Hz}$.

Data acquisition and analysis. Intracellular signals were buffered at $1 \times$ gain by an operational amplifier (OPA129U-ND, Digi-Key), head mounted on the microdrive, then fed into a single-channel intracellular amplifier with $10 \times$ amplification (IR-183, Cygnus Technology), and amplified $(15 \times)$ and digitized at 32,556 Hz (Digital Lynx, Neuralynx). Extracellular signals were amplified $20 \times$ by a head-mounted analog amplifier (HST/16V-G20, Plexon) and amplified $15 \times$ and digitized at $32,556 \mathrm{~Hz}$ (Digital Lynx, Neuralynx).

The 11 CA1 pyramidal neurons included in the present study were acquired from seven mice, out of a total of 60 mice in which recordings were attempted, over a total of $>150$ recording days. The distance from the brain surface was used to successfully target the CA1 pyramidal layer, and each included neuron showed intracellularly recorded ripples in its membrane potential $(\mathrm{Vm})$ at ripple frequency. Neither neocortical nor CA3 pyramidal cells show spike phase locking to LFP ripples in CA1 (Sullivan et al., 2011). In contrast, all included pyramidal cells did, identifying them as CA1 neurons. Only sections of recordings with no applied bias current were included in the analysis, except in Figure $4 G$, where negative current injection was used to hold the neuron Vm at hyperpolarized potentials. We excluded from analysis neurons that had a recording time of $<5$ min with no bias current or had spikes with action 
potentials $<45 \mathrm{mV}$. All analyses were performed under Matlab (Mathworks) using built-in and custom-made programs. For ripple detection, a threshold function (LFP, $>3 \mathrm{SD} ; \mathrm{Vm}:>6 \mathrm{SD}$ ) was applied to bandpassfiltered $(100-250 \mathrm{~Hz}) \mathrm{LFP}$ and Vm signals. The maximum negative or positive peak in each event detected in the filtered signals was taken as the center of the LFP or Vm ripple, respectively (Patel et al., 2013). Action potential threshold was determined from the time of the first positive peak in the third derivative of the spike waveform (Henze and Buzsáki, 2001). The percentage of time the $\mathrm{Vm}$ was above threshold without spiking was calculated from the portion of the $\mathrm{Vm}$ distribution that was greater than the lowest $5 \%$ of the spike threshold distribution. This value was calculated for each cell and for ripples and control periods independently. The difference in input resistance during ripples was calculated by fitting a single exponential to the first $15 \mathrm{~ms}$ of the charging curve of Vm during the beginning of randomly applied hyperpolarizing current pulses (180 pA to $1.4 \mathrm{nA}$ ). Current pulses that coincided with ripples were defined as such when the peak time of an LFP-detected ripple fell within a window of -5 to $+15 \mathrm{~ms}$ from the start time of the current injection. Paired control pulses were taken as the immediately preceding pulse.

In a separate group of mice, recordings from the CA1 pyramidal layer made using silicon electrodes (Stark et al., 2014) were used to analyze the waveform constancy during and outside ripples. For each well isolated unit, spike waveforms were recorded on 8-10 sites and projected onto a common basis (obtained by the principal component analysis of the data) consisting of three eigenvectors per site. The projection coefficients were then averaged over all spikes that occurred during/outside ripples to arrive at two mean waveform description vectors, which were then Pearson correlated and Fisher $Z$ transformed, yielding a "waveform consistency" measure. For a given unit, statistical significance of the consistency was assessed by randomly permuting the labels of spikes (during/outside ripples) and repeating the computation 1000 times.

Histology. Mice were anesthetized with pentobarbital injection, perfused with saline and 4\% paraformaldehyde before their brains were rapidly removed. Coronal sections $(100 \mu \mathrm{m})$ were cut on a vibratome (Leica, VT1000S) and collected in PBS. After three washes in PBS (15 min each), sections were permeabilized in PBS containing $0.2 \%$ gelatin and $0.2 \%$ Triton $\mathrm{X}-100\left(\mathrm{PBS}^{*}\right)$ for $2 \mathrm{~h}$ at room temperature and then incubated in streptavidin-conjugated Alexa555 diluted 1:500 in $\mathrm{PBS}^{*}$ for $3 \mathrm{~h}$. After two washes with PBS (30 min each) sections were incubated with 1:20,000 dilute DAPI in PBS and washed again for $30 \mathrm{~min}$, after which they were mounted in Fluoromount (Sigma-Aldrich) and imaged with a confocal microscope (LSM 510, Zeiss).

All experiments were approved by the institutional Animal Care and Use Committee of New York University Medical Center.

\section{Results}

\section{Intracellular activity during sharp wave ripples in CA1 pyramidal cells in freely behaving mice}

We combined LFP recording with intracellular monitoring of CA1 pyramidal neuron Vm in freely behaving animals. The intracellular recording glass pipette was advanced by a chronically implantable, motorized, and head-mountable, ultralight microdrive (Long et al., 2010; Fig. 1A, top). Impalement and stabilization of the neurons were performed as described previously in anesthetized animals (Ylinen et al., 1995). Our preparation resulted in stable recording of CAl pyramidal neuron Vm, lasting $\geq 2 \mathrm{~h}$ (Table 1). During all recording sessions animals were free to explore a $30 \times 30 \mathrm{~cm}$ recording chamber (Fig. $1 \mathrm{~A}$, bottom), in which they occasionally fell asleep, exhibiting rapid eye movement and slow-wave sleep epochs (Fig. 1B). Sharp wave ripple events were readily apparent in the pyramidal layer LFP (Fig. 1, blue traces) and in the intracellular Vm (Fig. 1, red traces).

While the sharp wave and ripple are distinct events, their close relationship is reflected by their similar time course and the correlation between the amplitude of the sharp waves and the magnitude and frequency of the ripples (Buzsáki, 1986; Sullivan et al.,
2011). A ripple event or episode consists of multiple ripple waves (typically 4-10), whose envelope defines the episode. Both sharp wave-related depolarization and ripple frequency oscillations were consistently observed in the intracellular recordings in the form of somatic depolarization and a fast, ripple-related Vm fluctuation, coincident with the LFP ripple event (Figs. $1 B-D, 2 A-C$ ). The trough (for LFP), or peak (for Vm), of the largest amplitude ripple wave within a filtered ripple episode $(100-250 \mathrm{~Hz})$ was considered the center of the ripple episode. Using the intracellularly detected ripples, ripple-triggered Vm signal revealed the true magnitude of the ripple event-related depolarization (mean peak, $+10.46 \mathrm{mV}$; SEM, $\pm 3.11 \mathrm{mV}$; using $6 \mathrm{SD}$ threshold for ripple detection; Fig. $2 B$, right). The intracellular and LFP ripples had the same peak frequency as quantified by wavelet spectra $(\mathrm{LFP}, 143.41 \pm 7.32 \mathrm{~Hz} ; \mathrm{Vm}, 142.27 \pm 57.63 \mathrm{~Hz} ; p=0.95, n=$ 11; Fig. 2C).

We examined the temporal relationship between intracellular and LFP events in three different ways. First, ripple trough times of the LFP were used to average both periripple LFP and Vm, which revealed similar and correlated waveforms of the extracellular and intracellular signals (Fig. $2 B$, left; $n=11$ neurons). Second, coherence spectra between LFP and Vm showed specific, though modest, ripple band-related increase (Fig. 2C, bottom). Third, separately detected LFP and Vm ripple times were crosscorrelated and these calculations also showed a robust but noisy peak in the cross-correlogram (Fig. 2D). Due to the disparity of recording times, the number of $\mathrm{Vm}$ ripples inevitably varied across neurons. However, when we confined our analysis to neurons with $\geq 10$ ripples $(n=7$; Table 1$)$, the results remained unaltered. Overall, these observations show that sharp waveinduced depolarization and ripple occurrence in the Vm of pyramidal neurons regularly accompany LFP ripples.

\section{Inhibition of pyramidal neurons during and after ripples}

During ripples, both pyramidal cells and various subclasses of interneurons increase their average firing rates but the ripplerelated gain is larger for pyramidal cells than for interneurons (Ylinen et al., 1995; Csicsvari et al., 1999a; Klausberger et al., 2003). In the absence of voltage-clamp separation of excitatory and inhibitory currents, we assessed their contributions indirectly in sharp electrode recordings. Vm was consistently depolarized during ripples (Vm ripple time; Fig. 3A). During ripples, Vm was significantly more likely to be above a minimum spike threshold value (see Materials and Methods) compared with control periods (Fig. 3C; mean \pm SEM: ripples with spikes, $49 \pm$ $14 \%$; control, $7 \pm 4 \%$; $p=0.0063$, paired $t$ test, $n=10$ neurons; ripples without spikes, $54 \pm 15 \%$; control, $17 \pm 12 \%$; $p=0.040$, paired $t$ test, $n=10$ neurons). This behavior of Vm suggests that during ripples pyramidal cells are always excited or that excitation is compensated for by concurrent inhibition. The third possibility, that inhibition depolarizes the neuronal membrane even above the resting membrane potential, was excluded by previous experiments performed under anesthesia (Ylinen et al., 1995).

To probe the presence and magnitude of inhibition during and after ripples, depolarizing current pulses (above rheobase) were injected into the soma of pyramidal neurons and the evoked firing rates were compared with control current-induced spiking epochs in the absence of ripples (Fig. $4 A ; 300 \mathrm{~ms}$ pulses at $0.1-0.5$ $\mathrm{Hz}, n=4$ cells). Because CA1 pyramidal neurons show rapid spike frequency adaptation (Fig. 4A-D; Lanthorn et al., 1984; Fernandez et al., 2011), and because ripples could occur any time during the current pulse, firing rate measurements in the control pulse-induced events were matched to the time and duration of 
A

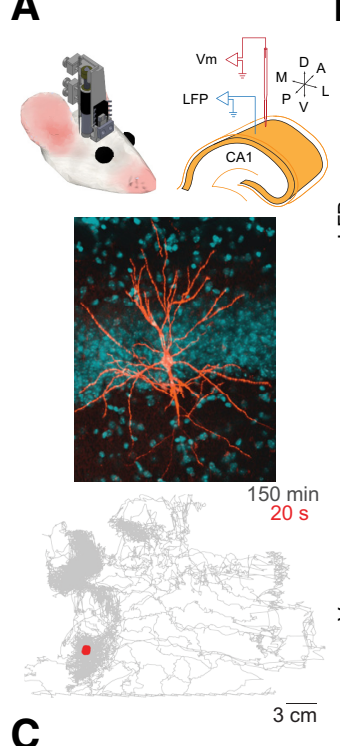

B

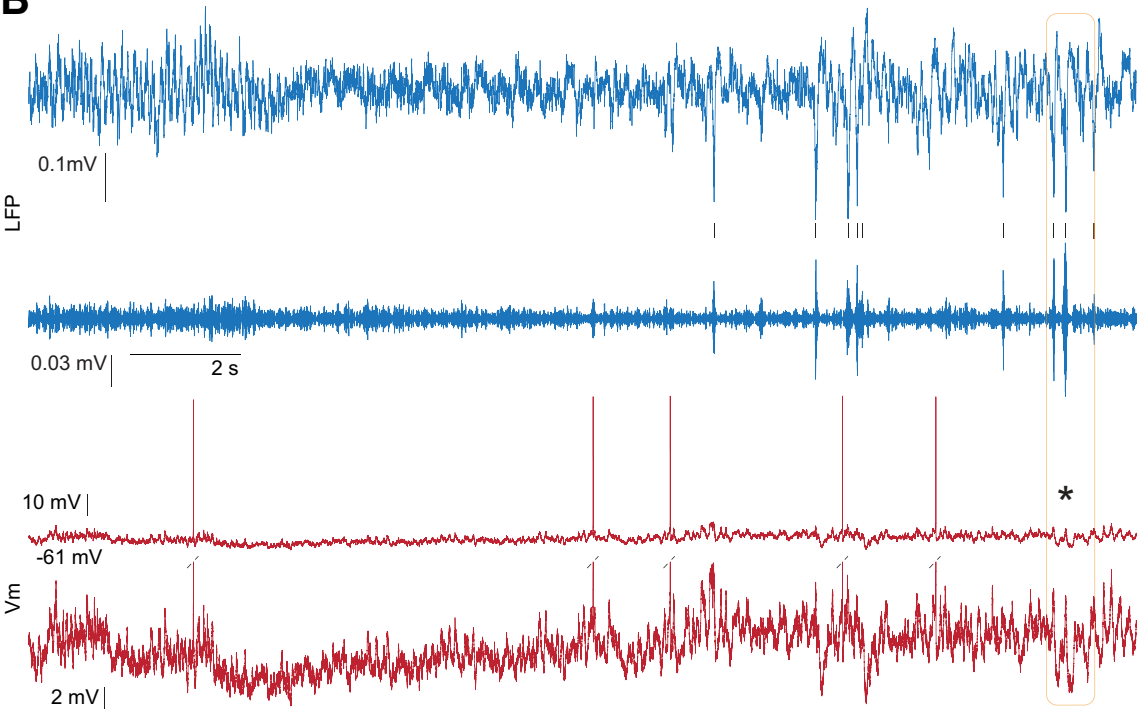

D

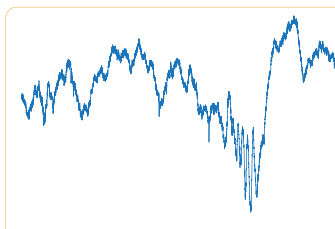

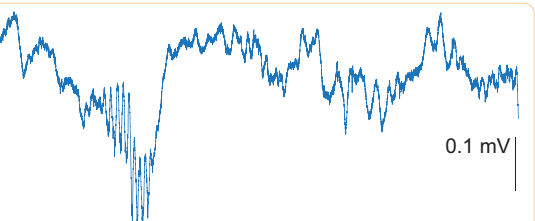

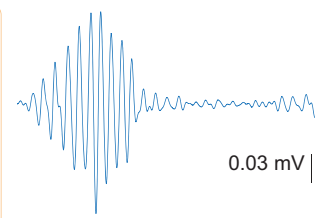

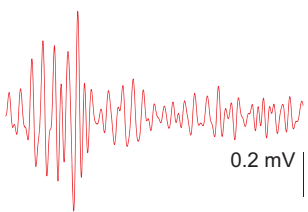
-60 mv
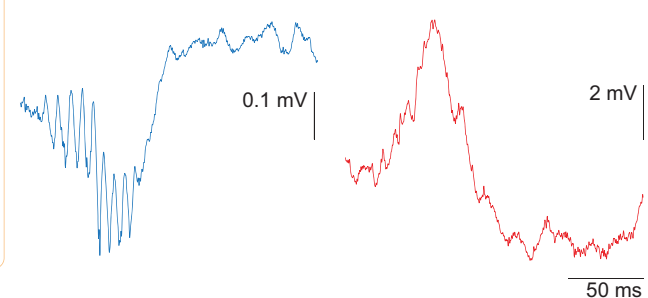

Figure 1. Simultaneous intracellular recording from CA1 pyramidal neuron and local field potential in freely behaving mouse. $A$, Top, Diagram of the microdrive positioned on the head of the mouse (left); scheme of the electrode arrangement in the dorsal CA1 pyramidal layer (right). Middle, Photomicrograph of a pyramidal neuron filled with biocytin during recording (Table 1, neuron \#8); biocytin-Alexa555 pseudocolored orange, DAPI pseudocolored blue. Note that the traces in the rest of this figure were recorded from a different neuron (Table 1, neuron \#9). Bottom, Record of animal position taken from head-mounted LEDs while the neuron, shown in $\boldsymbol{B}-\boldsymbol{D}$, was recorded for $150 \mathrm{~min}$. Red area is $20 \mathrm{~s}$ period shown in $\boldsymbol{B}$. $\boldsymbol{B}$, Intracellular sharp electrode recording of the $\mathbf{V m}$ (red) and LFP (blue) during transition from rapid eye movement to slow-wave sleep. The intracellular trace is shown at low (top trace) and high (bottom trace) magnifications with clipped spikes. LFP recorded in the CA1 pyramidal layer is shown both as wide-band (top) and $100-250 \mathrm{~Hz}$ filtered (bottom) traces. Black ticks mark the time of ripples detected in the LFP. C, Expanded view of a section of $\boldsymbol{B}$ (orange box) to illustrate two incidences of sharp wave ripple events apparent in LFP (blue) and Vm (red). $\boldsymbol{D}$, Expanded view of the ripple event marked by the black asterisk in $\boldsymbol{B}$ and $\boldsymbol{C}$. Top, $100-250 \mathrm{~Hz}$ filtered LFP (blue) and Vm (red). Bottom, Wide-band LFP (blue) and Vm (red). Note that the ripple oscillation in the LFP is accompanied by a corresponding oscillation in Vm on the rising phase of the intracellular sharp wave.

the sample LFP ripple event. This approach allowed us to compare spike rate changes at comparable epochs of the currentinduced pulse with and without concurrent ripples. Note that this approach is formally similar to the theoretical possibility of timing the ripple to different parts of the current-induced pulse. The current-induced firing rate was significantly lower when ripples (detected by the LFP recording electrode) were coincident with the current pulses than at similar (control) times in the absence of ripples (Fig. 4B; two-way ANOVA, ripple $p=0.0051$, time $p=2.4 \mathrm{e}-7$, interaction $p=0.96, n=4$ neurons). It should be noted that the ripple-related spike suppression is likely stronger than that reflected in Figure $4 B$ since the timing relationship of ripples recorded at different positions in the septotemporal axis varies extensively (Fig. 4A; Patel et al., 2013). The input resistance was observed to be lower during ripples (mean percentage decrease, $25.53 \%$; SEM, $0.62 \% ; p=0.042, n=3$ ), supporting the hypothesis that ripples are a high-conductance state. These observations suggest that during ripples a strong inhibition effectively disconnects the spike generation zone from the soma, allowing for the neuron to be depolarized above spike threshold yet without generating an action potential (Yu et al., 2008).

Ripples were consistently followed by hyperpolarization of Vm (Figs. 1,2), during which time the firing rate was significantly reduced compared with a preripple control period (Fig. $4 C$; twoway ANOVA ripple $p=0.03$, time $p=5.4 \mathrm{e}-7$, interaction $p=$ $0.89, n=4$ neurons). The power of the ripple oscillation in the $\mathrm{Vm}$ was correlated with the magnitude of the postripple hyperpolarization (Fig. $4 E$ ), and the time course of this correlation was similar to the time course of the average of the postripple $\mathrm{Vm}$ (Fig. 4F; $n=10$ neurons). The postripple $\mathrm{Vm}$ was similar for ripples with and without spikes, suggesting that the postripple inhibition is not dependent on spiking (Fig. $4 F$, red with spikes, green without spikes; $n=10$ neurons). The postripple hyperpolarization reversed at $\sim 80 \mathrm{mV}$ (Fig. $4 G ; n=2$ neurons), suggesting that an active 


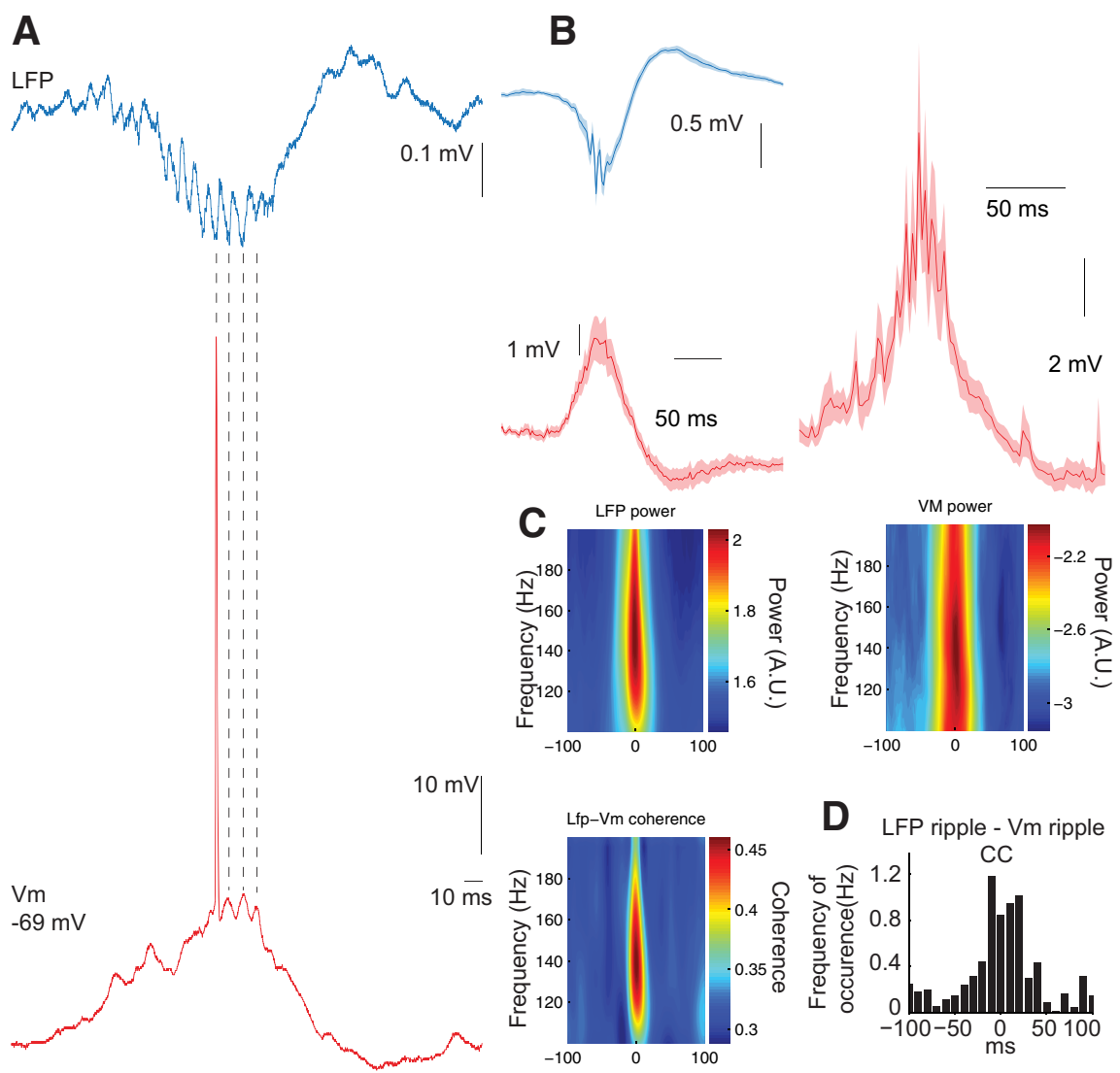

Figure 2. LFP ripples are correlated and coherent with ripple oscillations in the membrane potential of CA1 pyramidal neurons. $A$, Example trace demonstrating cycle-by-cycle temporal relationship between LFP and Vm ripples. $B$, Left, Average of LFP and Vm triggered on the negative peak of the LFP ripple for 11 neurons. Right, Intracellular ripple-triggered Vm to illustrate the average size of ripple-related depolarization ( $n=11$ neurons). Shaded area is SEM. C, Wavelet spectra and coherence between LFP and Vm during ripples detected in the LFP for 11 neurons. Mean peak frequency is the same in LFP and Vm. $p=0.95, n=11$ neurons. $\boldsymbol{D}$, Cross-correlation between ripples detected in the LFP and ripples detected in the $V m$ for 11 neurons. $\boldsymbol{B}-\boldsymbol{D}, 66-952$ LFP ripples and 2-294 Vm ripples per neuron. current rather than a decrease in excitation was responsible. These results suggest that a synaptically activated active current is responsible for the postripple hyperpolarization.

\section{Characteristics of pyramidal neuron action potentials during ripples}

Intracellularly recorded action potentials in the drug-free intact animal offered the opportunity to test the hypothesis that spikes during ripples invade the soma antidromically from the postulated gap junction-connected axonal nets (Schmitz et al., 2001; Maier et al., 2003; Bähner et al., 2011; Traub et al., 2012). Action potential waveforms during ripples and outside ripples (excluding burst spikes) were both found to be orthodromic (Fig. 5A-C; $n=10$ neurons). Action potential threshold was significantly higher during ripples (Fig. $5 D ; p=0.0021, n=10$ neurons). However, the peak voltage, width, rising slope, and falling slope were not significantly different (Fig. 5D). Firing rate increased substantially during ripples (Table 1).

To examine spike waveforms in a larger database, extracellular spikes were recorded in separate experiments using silicon probes in freely moving mice (Fig. $5 E)$. We found no significant difference in extracellular waveforms between spikes in ripples and outside ripples (Fig. 5E; waveform consistency, see Materials and Methods, $p=0.82, n=140$ neurons from nine mice). Based on our findings, it is unlikely that the mechanism of action potential generation during ripples is unique.
A

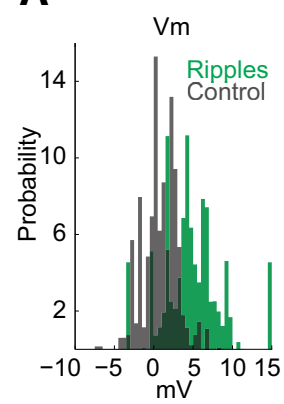

B

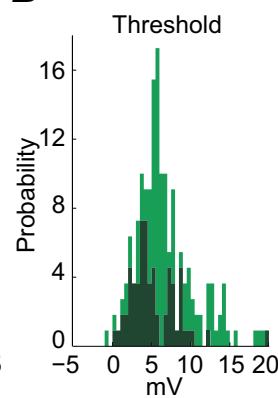

Figure 3. Ripples increase spike threshold. $\boldsymbol{A}$, Vm distribution in ripples (detected in the Vm; green) and during corresponding preripple control intervals (gray); $n=11$ neurons. A baseline value (mean of Vm sampled from a $500 \mathrm{~ms}$ window at -1000 ms before ripple peak time) was subtracted from each ripple Vm value (ripple Vm was determined from a $30 \mathrm{~ms}$ window at $-10 \mathrm{~ms}$ before ripple peak time) and from the preripple control $\mathrm{Vm}$ value (control Vm was a $50 \mathrm{~ms}$ window at $-110 \mathrm{~ms}$ from ripple peak time) to control for potential DC drift. Spikes (Vm from -2 to $+3 \mathrm{~ms}$ from spike time) were excluded. $\boldsymbol{B}$, Threshold distribution in ripples (green) and out of ripples (gray), $n=10$ neurons. $\boldsymbol{C}$, Percentage of time above threshold without spiking during ripples (green) and during preripple control intervals (gray), for ripples with spikes (left; $p=0.0063$ ) and for ripples without spikes (right; $p=0.040$ ); calculated independently for each neuron; $n=10$ neurons.

\section{Discussion}

The present data are the first example of intracellular recordings of sharp wave ripples using sharp glass electrodes from freely moving mice, although whole-cell recordings have been obtained in freely moving rats (Lee et al., 2006). Using this technique, we observed in CA1 pyramidal cells during sharp wave ripples large depolarizations associated with ripple frequency fluctuation of the Vm ("intracellular ripple"). Despite the consistent depolarization, often exceeding preripple spike threshold values, current-induced spikes were strongly suppressed, indicating the presence of concurrent shunting inhibition. Ripple events were followed by a prominent afterhyperpolarization and spike suppression. The waveforms of action potentials during and outside ripples were both found to be orthodromic, arguing against the possibility of ectopic spike generation.

Several recent experiments have pointed out significant differences between observations in anesthetized and drug-free animals, including the theta phase relationship of various interneuron types (Royer et al., 2012) and their firing patterns during sharp wave ripples (Varga et al., 2012). In a previous intracellular study performed under halothane anesthesia, ripple oscillations were completely abolished, although sharp waves and population discharges continued to occur (Ylinen et al., 1995). Under urethane anesthesia, sharp wave ripples occurred at a low 

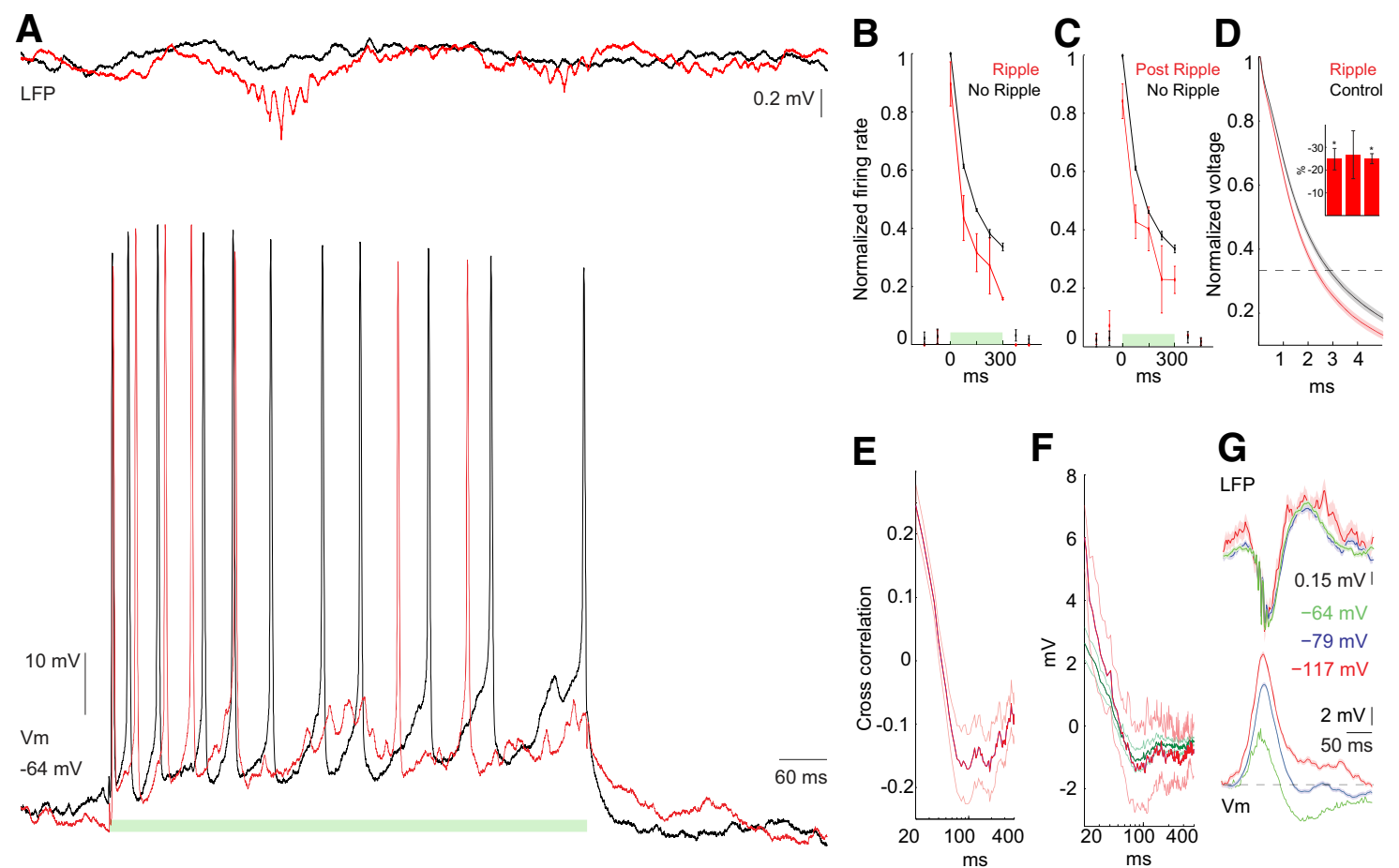

Figure 4. Ripple-associated inhibition of spiking. $\boldsymbol{A}$, Example traces of Vm and LFP during $300 \mathrm{~ms}$ current injections ( $\boldsymbol{A}-\boldsymbol{C}$, green bar), during ripple (red) and in the absence of a ripple (black). $\boldsymbol{B}$, Firing rate during ripples occurring during the $300 \mathrm{~ms}$ injection time. Rates during ripple-containing trials were determined from a window $\pm 25 \mathrm{~ms}$ from the ripple peak detected in the LFP. No ripple control is from matched periods with no ripples. Firing rate is normalized to the maximum firing rate during the first bin during current injection in the absence of ripples. Two-way ANOVA, ripple $p=0.0051$, time $p=2.4 \mathrm{e}-7$, interaction $p=0.96, n=4$ neurons. C, Similar to $B$ but postripple firing rates were determined $150 \mathrm{~ms}$ after ripple peak in \pm 25 ms windows. Two-way ANOVA ripple $p=0.03$, time $p=5.4$ e-7, interaction $p=0.89, n=4$ neurons. $\boldsymbol{D}$, Normalized voltage response to negative current injection to determine input resistance during ripples. Traces are example of one cell. Red is for current injections when an LFP ripple peak occurred within a window of -5 to $+20 \mathrm{~ms}$ from the start of the current pulse. Black is for the immediately preceding pulse. Shaded area is SEM. Inset is the percentage decrease in input resistance during ripples for three cells. ${ }^{*} p<0.005, n=32,3,34$. Mean percentage decrease, $25.53 \% ; S E M, 0.62 \% ; p=0.042, n=3$ neurons. $\boldsymbol{E}$, Correlation between Vm ripple power $(100-200 \mathrm{~Hz}$ ) and postripple $V m$ as a function of time; red is mean; light red lines are SEM; $n=11$ neurons. $F$, LFP ripple-triggered average of postripple Vm. Ripples with spikes: mean (red) and SEM (light red); ripples with no spikes: mean (dark green) and SEM (green); $n=10$ neurons. G, LFP ripple-triggered average of LFP and Vm at rest ( -64 $\mathrm{mV}$ ) and during two levels of negative current injection (resulting in $-79 \mathrm{mV},-117 \mathrm{mV}) ; n=2$ neurons.

rate and the oscillations slowed below $100 \mathrm{~Hz}$ (Ylinen et al., 1995). In our experiments, the intracellular and extracellular electrodes were placed $\sim 0.5-1 \mathrm{~mm}$ apart, corresponding to $10-$ $20 \%$ of the longitudinal axis $(\sim 5 \mathrm{~mm})$ of the hippocampus. Experiments in rats have shown that ripples are largely locally generated and propagate along the long axis of the hippocampus to various distances (Patel et al., 2013). As a result, ripples recorded at $>0.5 \mathrm{~mm}$ distance may have limited ripple wave synchrony, as illustrated by the relatively low ripple coherence between LFP ripples and intracellular Vm, despite the similar frequency bands of the extracellular and intracellular events. Such distance-related synchrony-attenuation of ripples might explain the relatively low incidence of co-occurrence and coherence of intracellularly and extracellularly detected ripples. Importantly, the intracellular ripples were often an order of magnitude larger (i.e., in the millivolt range) than the LFP ripples, excluding the possibility that the intracellular detected ripple simply reflects ephaptic effects of synchronous spikes of nearby pyramidal neurons (Buzsáki, 1986; Schomburg et al., 2012).

The role of inhibition in ripple generation and timing have been portrayed differently in previous in vivo experiments (Buzsáki et al., 1992; Ylinen et al., 1995; Csicsvari et al., 1999a; Klausberger et al., 2003; Klausberger and Somogyi, 2008; Rácz et al., 2009; Varga et al., 2012), in vitro experiments (Maier et al., 2003; Ellender et al., 2010; Bähner et al., 2011; Hájos et al., 2013; Karlócai et al., 2014), and computational models (Traub et al., 1996; Brunel and Hakim, 1999; Geisler et al., 2005; Taxidis et al., 2012).
Some studies dismissed the importance of inhibition (Draguhn et al., 1998; Jones and Barth, 2002; Maier et al., 2011), because fast oscillations could be induced by a local puff of $\mathrm{KCl}$ even after blockade of $\mathrm{GABA}_{\mathrm{A}}$ receptors (Nimmrich et al., 2005). It is important to note that while much has been learned about ripples from in vitro preparations, differences between in vitro and in vivo preparations, while not specific to the hippocampus or to ripplegeneration mechanisms, have been well demonstrated across many brain areas. Input resistance of neurons in the quiescent slice is known to be higher than in the active intact brain due to decreased activity of synaptic conductances and synaptic transmission (Paré et al., 1998). Also, active membrane dynamics are exquisitely sensitive to the concentrations of ions in the extracellular space/aCSF. For example $\mathrm{K}^{+}$and $\mathrm{Ca}^{2+}$ concentrations are hard to precisely replicate in the slice. $\mathrm{K}^{+}$affects overall excitability by modulating polarization, as well as having other effects. Meanwhile, $\mathrm{Ca}^{2+}$ regulates synaptic release and numerous other functions. $\mathrm{Ca}^{2+}$, like other divalent cations, also modulates disynaptic transmission by affecting spike threshold, which has recently been shown to modulate in vitro ripples (Aivar et al., 2014). Thus, an important goal of the present study was to compare ripples observed in in vitro slice experiments with ripples in the intact drug-free brain.

During the sharp wave ripple, both excitation and inhibition are increased (Csicsvari et al., 1999b), and a high-conductance state such as this can effectively shunt the membrane (Paré et al., 1998). In the present in vivo intracellular study, three sets of 
A

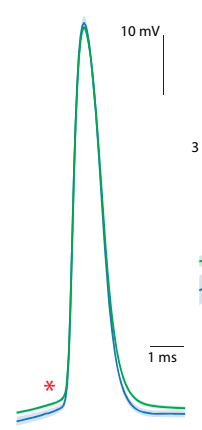

B

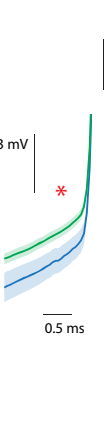

$2 \mathrm{~V} / \mathrm{s}$

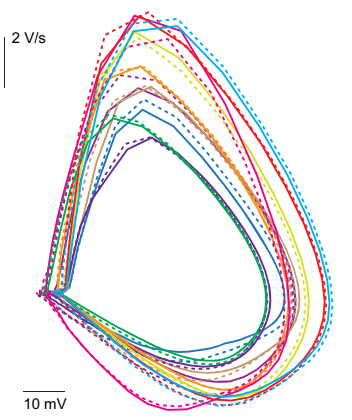

C

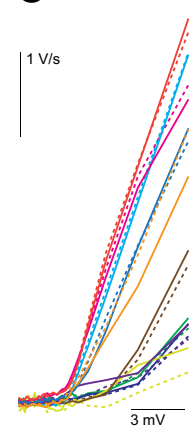

E

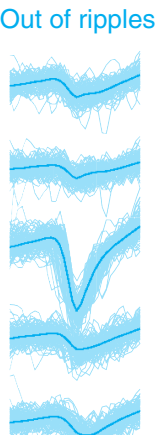

D
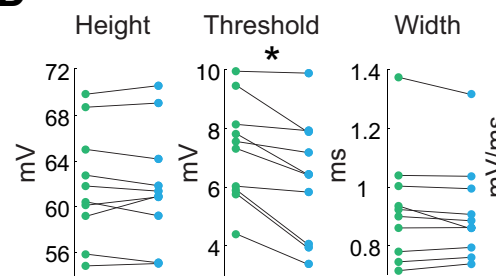

Rising slope Falling slope
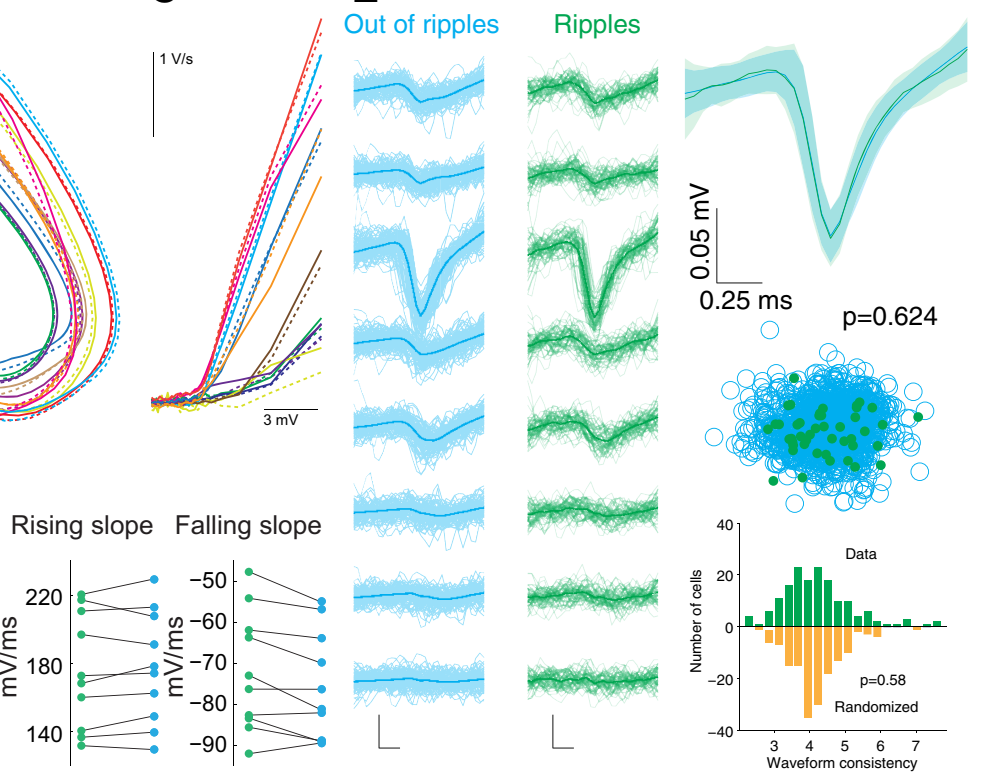

Figure 5. Action potential properties in and out of ripples. A, Left, Example waveforms of average action potential (AP) during ripples (green) and nonripple periods (blue) from one neuron. Right, Expanded view of the spike pair at left to illustrate the difference in threshold. Ripple periods are defined from the times are the peaks of the ripples detected in the LFP. Shaded area is SEM. $\boldsymbol{B}$, Phase plane plot of average AP waveforms. Each color is one neuron; solid lines are out of ripples; dashed lines are in ripples; $n=10$ neurons. $\boldsymbol{C}$, Expanded view of section phase plane plot with spike amplitude normalized across neurons to illustrate the shape near threshold. $D$, AP height (peak height, $p=0.91)$, threshold $(p=0.0021)$, width at half-height $(p=0.88)$, rising slope ( 0.90$)$, and falling slope ( $p=0.62$ ) in (green) and out (blue) of ripples ( $n=10$ neurons). $\boldsymbol{E}$, Top Left, Example extracellular spike waveforms are similar during ripples (green) and outside ripples (blue), as recorded with silicon probes. Top right, Averages recorded from the largest amplitude site in and out of ripples are superimposed. Bottom left, Unit cluster cloud comparing spikes in and out of ripples; $p=0.624$ (permutation test). Bottom right, Comparison of 160 well isolated neurons from nine freely moving mice; $p=0.82$ (Wilcoxon's paired signed-rank test).

observations illustrate the various roles of inhibition. First, the ripple-coherent fast oscillation of $\mathrm{Vm}$ is likely a reflection of the rhythmic, basket interneuron firing-induced IPSPs (Buzsáki et al., 1992; Ylinen et al., 1995; Csicsvari et al., 1999a, b; Klausberger et al., 2003; Maier et al., 2003, 2011; Klausberger and Somogyi, 2008; Rácz et al., 2009; Bähner et al., 2011; Varga et al., 2012; Hájos et al., 2013; Karlócai et al., 2014). Second, spike threshold was elevated during ripples. Spike threshold variability can emerge from $\geq 2$ different mechanisms. First, spiking activity decreases the availability of $\mathrm{Na}^{+}$channels (Henze and Buzsáki, 2001). However, spiking history alone cannot explain elevated spike thresholds during ripples since Vm during ripples often exceeded the spike threshold regardless of the presence or absence of spikes. Another mechanism that can increase the spike threshold is shunting inhibition of the soma, which can functionally disconnect the spike generation region in the axon initial segment from the soma (Yu et al., 2008). Thus, shunting inhibition can explain why spike threshold during ripples is elevated. Third, the most explicit demonstration of strong inhibitory action during ripples is the suppression of current-induced spiking (Fig. 4A,B). These findings support the view that during sharp wave ripples inhibition is strongly elevated, concurrent with strong excitation (Csicsvari et al., 1999b; Csicsvari and Dupret, 2014). Silencing of chandelier cells may also contribute to the elevated discharge of pyramidal cells during ripples (Viney et al., 2013). In summary, during ripples, a complex set of mechanisms is in action. These mechanisms include dendritic excitation and somatic inhibition, each of which can contribute to the shunting. Mechanisms can also include transient removal of inhibition from the axon initial segment. Because of the excitation-induced depolarization, the initial shunting inhibition at resting Vm may be converted to hyperpolarizing inhibition during the course of the ripple.
We additionally observed that inhibition outlasted the sharp wave-ripple depolarization. We observed robust hyperpolarizations in our intracellular recording after ripples with more negative than $-80 \mathrm{mV}$ polarity reversal, indicating the presence of an active $\mathrm{K}^{+}$current (Ling and Benardo, 1994). Because afterhyperpolarization was present regardless of whether the neuron spiked or not, this observation favors synaptic mechanisms rather than the contribution of intrinsic conductances. A potential synaptic mechanism for the ripple afterhyperpolarization is $\mathrm{GABA}_{\mathrm{B}}$ receptor-mediated inhibition (Scanziani, 2000), which stems from intense GABA release during the ripple by the highly active GABAergic interneurons. In support of the active inhibition hypothesis, current-induced spiking was strongly suppressed during the postripple period. These observations suggest that a network-level process introduces a postripple refractory period that may serve to ensure adequate temporal separation between individual ripple events.

A prominent computational model of ripple generation suggests that axo-axonal gap junctions connect the CA1 pyramidal neurons into a sparse electrically coupled network. The key assumptions of this model are that spikes in the axonal plexus excite pyramidal cells and backpropagate antidromically from ectopic sites of spike generation to the soma, and that the speed of propagation in the axonal network and the connectivity sparseness sets the ripple frequency (Draguhn et al., 1998; Traub and Bibbig, 2000; Traub et al., 2003). An explicit prediction of this model is the presence of antidromic spikes during ripples. In support of this prediction, recent studies have shown that spikes during ripple-like bursts in vitro were generated in the axon without prior depolarization of the soma, as evidenced by the antidromic spikes in the soma, in contrast to action potentials outside ripples that rode on preceding Vm depolarization (Papatheodoropoulos, 2008; Bähner et al., 2011). In our experiments, the waveforms 
of the action potentials both in and outside ripples were absent of signs of axonal origin, including the critical prespike period. Extracellular recording and comparison of spike waveforms in a larger group of pyramidal cells found no significant difference in the waveforms of spikes in ripples and those out of ripples. These findings indicate that spikes in CA1 pyramidal cells are triggered orthodromically during ripples, likely driven by the CA3 excitatory input (Buzsàki, 1983; Csicsvari et al., 2000). Overall, our intracellular in vivo experiments support the view that during ripples, the sharp wave-associated excitation is accompanied by inhibition, which ultimately controls spiking. Most or all CA1 pyramidal neurons experience inhibition during ripple events and thus only a subset of the neurons reach spike threshold.

\section{References}

Aivar P, Valero M, Bellistri E, Menendez de la Prida L (2014) Extracellular calcium controls the expression of two different forms of ripple-like hippocampal oscillations. J Neurosci 34:2989-3004. CrossRef Medline

Bähner F, Weiss EK, Birke G, Maier N, Schmitz D, Rudolph U, Frotscher M, Traub RD, Both M, Draguhn A (2011) Cellular correlate of assembly formation in oscillating hippocampal networks in vitro. Proc Natl Acad Sci U S A 108:E607-E616. CrossRef Medline

Brunel N, Hakim V (1999) Fast global oscillations in networks of integrateand-fire neurons with low firing rates. Neural Comput 11:1621-1671. CrossRef Medline

Brunel N, Wang XJ (2003) What determines the frequency of fast network oscillations with irregular neural discharges? I. Synaptic dynamics and excitation-inhibition balance. J Neurophysiol 90:415-430. CrossRef Medline

Buzsàki G (1983) Situational conditional reflexes. Physiologic studies of the higher nervous activity of freely moving animals: P. S. Kupalov. Pavlov J Biol Sci 18:13-21. Medline

Buzsáki G (1986) Hippocampal sharp waves: their origin and significance. Brain Res 398:242-252. CrossRef Medline

Buzsáki G, Horváth Z, Urioste R, Hetke J, Wise K (1992) High-frequency network oscillation in the hippocampus. Science 256:1025-1027. CrossRef Medline

Chiovini B, Turi GF, Katona G, Kaszás A, Pálfi D, Maák P, Szalay G, Szabó MF, Szabó G, Szadai Z, Káli S, Rózsa B (2014) Dendritic spikes induce ripples in parvalbumin interneurons during hippocampal sharp waves. Neuron 82:908-924. CrossRef Medline

Csicsvari J, Dupret D (2014) Sharp wave/ripple network oscillations and learning-associated hippocampal maps. Philos Trans R Soc Lond B Biol Sci 369:20120528. CrossRef Medline

Csicsvari J, Hirase H, Czurkó A, Mamiya A, Buzsáki G (1999a) Oscillatory coupling of hippocampal pyramidal cells and interneurons in the behaving rat. J Neurosci 19:274-287. Medline

Csicsvari J, Hirase H, Czurkó A, Mamiya A, Buzsáki G (1999b) Fast network oscillations in the hippocampal CA1 region of the behaving rat. J Neurosci 19:RC20. Medline

Csicsvari J, Hirase H, Mamiya A, Buzsáki G (2000) Ensemble patterns of hippocampal CA3-CA1 neurons during sharp wave-associated population events. Neuron 28:585-594. CrossRef Medline

Diba K, Buzsáki G (2007) Forward and reverse hippocampal place-cell sequences during ripples. Nat Neurosci 10:1241-1242. CrossRef Medline

Draguhn A, Traub RD, Schmitz D, Jefferys JG (1998) Electrical coupling underlies high-frequency oscillations in the hippocampus in vitro. Nature 394:189-192. CrossRef Medline

Ego-Stengel V, Wilson MA (2010) Disruption of ripple-associated hippocampal activity during rest impairs spatial learning in the rat. Hippocampus 20:1-10. CrossRef Medline

Ellender TJ, Nissen W, Colgin LL, Mann EO, Paulsen O (2010) Priming of hippocampal population bursts by individual perisomatic-targeting interneurons. J Neurosci 30:5979-5991. CrossRef Medline

Fernandez FR, Broicher T, Truong A, White JA (2011) Membrane voltage fluctuations reduce spike frequency adaptation and preserve output gain in CA1 pyramidal neurons in a high-conductance state. J Neurosci 31: 3880-3893. CrossRef Medline

Foster DJ, Wilson MA (2006) Reverse replay of behavioural sequences in hippocampal place cells during the awake state. Nature 440:680-683. CrossRef Medline
Geisler C, Brunel N, Wang XJ (2005) Contributions of intrinsic membrane dynamics to fast network oscillations with irregular neuronal discharges. J Neurophysiol 94:4344-4361. CrossRef Medline

Girardeau G, Benchenane K, Wiener SI, Buzsáki G, Zugaro MB (2009) Selective suppression of hippocampal ripples impairs spatial memory. Nat Neurosci 12:1222-1223. CrossRef Medline

Gupta AS, van der Meer MA, Touretzky DS, Redish AD (2010) Hippocampal replay is not a simple function of experience. Neuron 65:695-705. CrossRef Medline

Hájos N, Karlócai MR, Németh B, Ulbert I, Monyer H, Szabó G, Erdélyi F, Freund TF, Gulyás AI (2013) Input-output features of anatomically identified CA3 neurons during hippocampal sharp wave/ripple oscillation in vitro. J Neurosci 33:11677-11691. CrossRef Medline

Henze DA, Buzsáki G (2001) Action potential threshold of hippocampal pyramidal cells in vivo is increased by recent spiking activity. Neuroscience 105:121-130. CrossRef Medline

Jadhav SP, Kemere C, German PW, Frank LM (2012) Awake hippocampal sharp-wave ripples support spatial memory. Science 336:1454-1458. CrossRef Medline

Johnson A, Redish AD (2005) Hippocampal replay contributes to within session learning in a temporal difference reinforcement learning model. Neural Netw 18:1163-1171. CrossRef Medline

Jones MS, Barth DS (2002) Effects of bicuculline methiodide on fast $(>200$ $\mathrm{Hz}$ ) electrical oscillations in rat somatosensory cortex. J Neurophysiol 88:1016-1025. Medline

Kamondi A, Acsády L, Buzsáki G (1998) Dendritic spikes are enhanced by cooperative network activity in the intact hippocampus. J Neurosci 18: 3919-3928. Medline

Karlócai MR, Kohus Z, Káli S, Ulbert I, Szabó G, Máté Z, Freund TF, Gulyás AI (2014) Physiological sharp wave-ripples and interictal events in vitro: what's the difference? Brain 137:463-485. CrossRef Medline

Karlsson MP, Frank LM (2009) Awake replay of remote experiences in the hippocampus. Nat Neurosci 12:913-918. CrossRef Medline

Klausberger T, Somogyi P (2008) Neuronal diversity and temporal dynamics: the unity of hippocampal circuit operations. Science 321:53-57. CrossRef Medline

Klausberger T, Magill PJ, Márton LF, Roberts JD, Cobden PM, Buzsáki G, Somogyi P (2003) Brain-state- and cell-type-specific firing of hippocampal interneurons in vivo. Nature 421:844-848. CrossRef Medline

Kudrimoti HS, Barnes CA, McNaughton BL (1999) Reactivation of hippocampal cell assemblies: effects of behavioral state, experience, and EEG dynamics. J Neurosci 19:4090-4101. Medline

Lanthorn T, Storm J, Andersen P (1984) Current-to-frequency transduction in CA1 hippocampal pyramidal cells: slow prepotentials dominate the primary range firing. Exp Brain Res 53:431-443. Medline

Lee AK, Wilson MA (2002) Memory of sequential experience in the hippocampus during slow wave sleep. Neuron 36:1183-1194. CrossRef Medline

Lee AK, Manns ID, Sakmann B, Brecht M (2006) Whole-cell recordings in freely moving rats. Neuron 51:399-407. CrossRef Medline

Ling DS, Benardo LS (1994) Properties of isolated GABAB-mediated inhibitory postsynaptic currents in hippocampal pyramidal cells. Neuroscience 63:937-944. CrossRef Medline

Long MA, Jin DZ, Fee MS (2010) Support for a synaptic chain model of neuronal sequence generation. Nature 468:394-399. CrossRef Medline

Maier N, Nimmrich V, Draguhn A (2003) Cellular and network mechanisms underlying spontaneous sharp wave-ripple complexes in mouse hippocampal slices. J Physiol 550:873-887. CrossRef Medline

Maier N, Tejero-Cantero A, Dorrn AL, Winterer J, Beed PS, Morris G, Kempter R, Poulet JF, Leibold C, Schmitz D (2011) Coherent phasic excitation during hippocampal ripples. Neuron 72:137-152. CrossRef Medline

Mizunuma M, Norimoto H, Tao K, Egawa T, Hanaoka K, Sakaguchi T, Hioki H, Kaneko T, Yamaguchi S, Nagano T, Matsuki N, Ikegaya Y (2014) Unbalanced excitability underlies offline reactivation of behaviorally activated neurons. Nat Neurosci 17:503-505. CrossRef Medline

Nádasdy Z, Hirase H, Czurkó A, Csicsvari J, Buzsáki G (1999) Replay and time compression of recurring spike sequences in the hippocampus. J Neurosci 19:9497-9507. Medline

Nimmrich V, Maier N, Schmitz D, Draguhn A (2005) Induced sharp waveripple complexes in the absence of synaptic inhibition in mouse hippocampal slices. J Physiol 563:663-670. CrossRef Medline 
O'Keefe JM, Nadel L (1978) The hippocampus as a cognitive map. New York: Oxford UP.

O'Neill J, Senior T, Csicsvari J (2006) Place-selective firing of CA1 pyramidal cells during sharp wave/ripple network patterns in exploratory behavior. Neuron 49:143-155. CrossRef Medline

Papatheodoropoulos C (2008) A possible role of ectopic action potentials in the in vitro hippocampal sharp wave-ripple complexes. Neuroscience 157:495-501. CrossRef Medline

Papatheodoropoulos C, Koniaris E (2011) alpha5GABAA receptors regulate hippocampal sharp wave-ripple activity in vitro. Neuropharmacology 60:662-673. CrossRef Medline

Paré D, Shink E, Gaudreau H, Destexhe A, Lang EJ (1998) Impact of spontaneous synaptic activity on the resting properties of cat neocortical pyramidal neurons in vivo. J Neurophysiol 79:1450-1460. Medline

Patel J, Schomburg EW, Berényi A, Fujisawa S, Buzsáki G (2013) Local generation and propagation of ripples along the septotemporal axis of the hippocampus. J Neurosci 33:17029-17041. CrossRef Medline

Quilichini P, Sirota A, Buzsáki G (2010) Intrinsic circuit organization and theta-gamma oscillation dynamics in the entorhinal cortex of the rat. J Neurosci 30:11128-11142. CrossRef Medline

Rácz A, Ponomarenko AA, Fuchs EC, Monyer H (2009) Augmented hippocampal ripple oscillations in mice with reduced fast excitation onto parvalbumin-positive cells. J Neurosci 29:2563-2568. CrossRef Medline

Royer S, Zemelman BV, Losonczy A, Kim J, Chance F, Magee JC, Buzsáki G (2012) Control of timing, rate and bursts of hippocampal place cells by dendritic and somatic inhibition. Nat Neurosci 15:769-775. CrossRef Medline

Scanziani M (2000) GABA spillover activates postsynaptic GABA(B) receptors to control rhythmic hippocampal activity. Neuron 25:673-681. CrossRef Medline

Schmitz D, Schuchmann S, Fisahn A, Draguhn A, Buhl EH, Petrasch-Parwez E, Dermietzel R, Heinemann U, Traub RD (2001) Axo-axonal coupling: a novel mechanism for ultrafast neuronal communication. Neuron 31: 831-840. CrossRef Medline

Schomburg EW, Anastassiou CA, Buzsáki G, Koch C (2012) The spiking component of oscillatory extracellular potentials in the rat hippocampus. J Neurosci 32:11798-11811. CrossRef Medline

Singer AC, Carr MF, Karlsson MP, Frank LM (2013) Hippocampal SWR activity predicts correct decisions during the initial learning of an alternation task. Neuron 77:1163-1173. CrossRef Medline

Stark E, Roux L, Eichler R, Senzai Y, Royer S, Buzsáki G (2014) Pyramidal cell-interneuron interactions underlie hippocampal ripple oscillations. Neuron 83:467-480. CrossRef 25033186
Sullivan D, Csicsvari J, Mizuseki K, Montgomery S, Diba K, Buzsáki G (2011) Relationships between hippocampal sharp waves, ripples, and fast gamma oscillation: influence of dentate and entorhinal cortical activity. J Neurosci 31:8605-8616. CrossRef Medline

Taxidis J, Coombes S, Mason R, Owen MR (2012) Modeling sharp waveripple complexes through a CA3-CA1 network model with chemical synapses. Hippocampus 22:995-1017. CrossRef Medline

Traub RD, Bibbig A (2000) A model of high-frequency ripples in the hippocampus based on synaptic coupling plus axon-axon gap junctions between pyramidal neurons. J Neurosci 20:2086-2093. Medline

Traub RD, Whittington MA, Stanford IM, Jefferys JG (1996) A mechanism for generation of long-range synchronous fast oscillations in the cortex. Nature 383:621-624. CrossRef Medline

Traub RD, Cunningham MO, Gloveli T, LeBeau FE, Bibbig A, Buhl EH, Whittington MA (2003) GABA-enhanced collective behavior in neuronal axons underlies persistent gamma-frequency oscillations. Proc Natl Acad Sci U S A 100:11047-11052. CrossRef Medline

Traub RD, Schmitz D, Maier N, Whittington MA, Draguhn A (2012) Axonal properties determine somatic firing in a model of in vitro CA1 hippocampal sharp wave/ripples and persistent gamma oscillations. Eur J Neurosci 36:2650-2660. CrossRef Medline

Varga C, Golshani P, Soltesz I (2012) Frequency-invariant temporal ordering of interneuronal discharges during hippocampal oscillations in awake mice. Proc Natl Acad Sci U S A 109:E2726-E2734. CrossRef Medline

Viney TJ, Lasztoczi B, Katona L, Crump MG, Tukker JJ, Klausberger T, Somogyi P (2013) Network state-dependent inhibition of identified hippocampal CA3 axo-axonic cells in vivo. Nat Neurosci 16:1802-1811. CrossRef Medline

Whittington MA, Traub RD, Jefferys JG (1995) Synchronized oscillations in interneuron networks driven by metabotropic glutamate receptor activation. Nature 373:612-615. CrossRef Medline

Wikenheiser AM, Redish AD (2013) The balance of forward and backward hippocampal sequences shifts across behavioral states. Hippocampus 23: 22-29. CrossRef Medline

Wilson MA, McNaughton BL (1994) Reactivation of hippocampal ensemble memories during sleep. Science 265:676-679. CrossRef Medline

Ylinen A, Bragin A, Nádasdy Z, Jandó G, Szabó I, Sik A, Buzsáki G (1995) Sharp wave-associated high-frequency oscillation $(200 \mathrm{~Hz})$ in the intact hippocampus: network and intracellular mechanisms. J Neurosci 15:3046. Medline

Yu Y, Shu Y, McCormick DA (2008) Cortical action potential backpropagation explains spike threshold variability and rapid-onset kinetics. J Neurosci 28:7260-7272. CrossRef Medline 